\title{
Pengalaman Fenomenologis Pertunjukan Reog Ponorogo dan Relevansinya terhadap Pendidikan Karakter
}

\author{
Fina Yuni Sriana, Trisakti, Setyo Yanuartuti \\ Program Pascasarjana Pendidikan Seni Budaya, Universitas Negeri Surabaya \\ finayunisriana@yahoo.com
}

Article History: Diterima (05 November 2019); Diperbaiki (27 Desember 2019); Disetujui (15 Januari 2020); Published (30 April 2020)

How to cite (in APA Style): Sriana, F. Y., Trisakti, Yanuartuti, S. (2020). Pengalaman Fenomenologis Pertunjukan Reog Ponorogo dan Relevansinya Terhadap Pendidikan Karakter. Lokabasa, 11(1), 38-49. doi: https://doi.org/10.17509/jlb.v11i1.25193

Abstrak: Penelitian ini membahas tentang relevansi pendidikan karakter melalui seni tradisi di Indonesia, dalam hal ini adalah Reog di Kabupaten Ponorogo. Lebih lanjut, penelitian ini juga mengeksplorasi pendidikan karakter melalui fenomenologi penubuhan dan transformasi pengalaman ke dalam pendidikan karakter yang terjadi ketika individu mengapresiasi pertunjukan Reog Ponorogo. Metode penelitian ini menggunakan kualitatif naturalistik, dengan pendekatan fenomenologis terhadap fenomena Reog Ponorogo dan keterkaitannya dengan pendidikan karakter. Data yang didapatkan dari observasi, wawancara, dan studi dokumentasi selanjutnya dianalisis secara deskriptif tentang kesejarahan Reog Ponorogo, pertunjukannya, pengalaman-pengalaman, dan relevansinya terhadap pendidikan karakter. Hasil menunjukkan bahwa pengalaman fenomenologis atas pertunjukan Reog Ponorogo memiliki relevansi terhadap pendidikan karakter dan pendidikan budaya melalui pendidikan yang memainkan peran utama dalam transmisi budaya. Pendidikan nasionalisme kearifan lokal juga dapat dijelaskan dengan baik oleh pertunjukan Reog Ponorogo melalui metafor-metafor dalam pertunjukannya sebagai simbol aspek yang akan dijelaskan kepada masyarakat. Terdapat pendidikan karakter di dalam pertunjukan Reog Ponorogo yang menciptakan suasana transformasi seni budaya menuju pendidikan karakter dengan mengembangkan lingkungan di mana pendekatan budaya sangat dipertimbangkan dan dipersiapkan dengan keterampilan serta praktik budaya sebagai pendukung media belajar generasi muda.

Kata Kunci: pendidikan karakter; pengalaman fenomenologis; pertunjukan; Reog Ponorogo

\section{Phenomenological Experience of Reog Ponorogo Performance and Its Relevance to Character Education}

Abstract: This study discusses the relevance of character education through traditional arts in Indonesia, in this case, Reog in Ponorogo Regency. Furthermore, this research also explores character education through the phenomenology of the body and the transformation of experience into character education that occurs when individuals appreciate the performance of Reog Ponorogo. This research method uses naturalistic qualitative, with a phenomenological approach to the Reog Ponorogo phenomenon and its relationship to character education. Data obtained from observations, interviews, and subsequent documentation studies were analyzed descriptively about the history of Reog Ponorogo, its performances, experiences, and its relevance to character education. The results show that the phenomenological experience of the Reog Ponorogo show has relevance to character education and cultural education through education which plays a major role in cultural transmission. The education of local wisdom nationalism can also be well explained by the Reog Ponorogo show through the metaphors in the show as a symbol of aspects that will be explained to the public. There is character education in the Reog Ponorogo performance which creates an atmosphere of the transformation of cultural arts and culture towards character education by developing an environment in which cultural approaches are highly considered and prepared with cultural skills and practices as supporting the learning media of the younger generation.

Keywords: character building; performing arts; phenomenological experience; Reog Ponorogo 


\section{PENDAHULUAN}

Pendidikan karakter merupakan salah satu bagian penting dalam proses perkembangan individu (Shields, 2015). Pendidikan karakter turut serta dalam mendukung tujuan pendidikan yaitu membantu individu berpengetahuan dan membantu individu menjadi pribadi yang baik untuk dirinya dan masyarakat sekitar (Rivers, 2016). Berdasarkan kepercayaan tersebut, lembaga pendidikan di masa-masa awal menangani pendidikan karakter secara langsung melalui tindakan disiplin, guru sebagai role model, dan kurikulum keseharian. Pendidikan karakter mampu memasuki ruang terdalam dari kepribadian individu dalam penggabungan melalui disiplin lain antara lain anak berlatih membaca atau berhitung sekaligus juga belajar pelajaran tentang kejujuran, cinta sesama, kebaikan pada makhluk hidup, kerja keras, penghematan, patriotisme, dan keberanian; yang biasa disebut dengan fleksibilitas interdisipliner (Moran, 2002; Rivers, 2016; Winataputra, 2008).

Seni merupakan suatu disiplin keilmuan yang memiliki fleksibilitas untuk berkolaborasi dengan disiplin lain dalam arena interdisiplin (Graham, 1997; M. B. T. Sampurno, 2017; T. Sampurno, 2015). Pendidikan seni interdisiplin merupakan salah satu bagian dalam pembelajaran yang terintegrasi dengan bidang lainnya untuk mencapai tujuan pendidikan, menambah pengetahuan, memberi pemahaman, dan pemunculan kajian ilmu dan pengetahuan baru (Bastos, 2010; Bowen \& Kisida, 2017; Eisenhauer, 2006; Hetrick, 2019). Pendidikan dalam marwah nasional berfungsi mengembangkan kemampuan dan membentuk watak serta peradaban bangsa yang bermartabat dalam rangka mencerdaskan kehidupan bangsa, bertujuan untuk berkembangnya potensi peserta didik agar menjadi manusia yang beriman dan bertakwa kepada Tuhan Yang Maha Esa, berakhlak mulia, sehat, berilmu, cakap, kreatif, mandiri, dan menjadi warga negara yang demokratis serta bertanggung jawab (Kuntz, 2014; Rivers, 2016; Suherman,
2018). Hal tersebut tentunya menunjukkan bahwa pendidikan karakter dan pendidikan seni saling berkelindan dan kolaboratif. Lebih lanjut, pendidikan seni hendaknya juga digunakan untuk mengenalkan kesenian daerah Indonesia. Seperti yang telah dituliskan dalam paragraf pertama, pendidikan karakter membuka dirinya untuk menyatu dan membaur dengan disiplin atau bidang keilmuan pendidikan lain. Oleh karena itu, kolaborasi pendidikan seni dan pendidikan karakter merupakan suatu kewajiban untuk dilakukan karena kesenian merupakan bagian yang penting dalam kultur suatu bangsa sekaligus membentuk karakter pribadi individu.

Tujuan pendidikan karakter melalui seni adalah sebagai bagian untuk mencapai tujuan pendidikan (Ambarwangi \& Suharto, 2014; Davies, Gorard, \& McGuinn, 2015; Shields, 2015). Seni merupakan alat untuk mencapai tujuan pendidikan yang di dalamnya tidak menuntut individu untuk menjadi seniman, namun lebih menitik-beratkan pada proses (Madeja, 2009). Di dalam proses pendidikan melalui seni tersebut individu dapat berkembang melalui berbagai proses pengalaman estetik (Dewey, 1980; Kraus, 2014). Lebih lanjut, melalui seni, individu diajarkan untuk mendapatkan pengalaman nyata dalam memahami seni tradisi di Indonesia. Melalui pengalaman nyata tersebut diharapkan dapat mengembangkan potensi yang mereka miliki. Seni sebagai dasar pendidikan pernah diungkapkan oleh Plato yang menyatakan bahwa "art should be the basis of education" (Graham, 1997; Read, 1970). Argumentasi tersebut bukan tanpa alasan, karena pendidikan seni mempunyai nilai tinggi dalam dunia pendidikan. Hal ini sejalan dengan tujuan pendidikan, yaitu untuk mendorong pertumbuhan individu dalam setiap manusia. Di saat yang sama harmonisasi individualitas sehingga dengan kesatuan organik dari kelompok sosial yang mengikuti dalam proses ini pendidikan estetika adalah pendidikan yang fundamental. Pendidikan karakter yang menekankan pada seni ditunjukkan dengan 
(1) pelestarian intensitas alamiah dari semua mode persepsi dan sensasi individu; (2) koordinasi berbagai mode persepsi dan sensasi satu sama lain dan dalam hubungan di lingkungan sekitar; (3) ekspresi perasaan dalam bentuk yang dapat dikomunikasikan; (4) ekspresi dalam bentuk atau cara-cara pengalaman mental yang dapat dikomunikasikan; dan (5) pengaktualisasian ekspresi pemikiran. Kelima hal di atas merupakan konsep dasar pendidikan karakter melalui seni, yang dibutuhkan dalam perkembangan individu di era disrupsi ini (Berkowitz \& Bier, 2014; Read, 1970; Shields, 2015).

Umumnya, individu sebagai bagian dari kebudayaan menghargai nilai keluhuran bangsa dengan mempelajari terlebih dahulu tentang kesenian rakyatnya (Timothy J. Bergen, 2014). Oleh karenanya merupakan hal yang positif apabila generasi penerus bangsa memahami kesenian daerah Indonesia sebagai tanda penghargaan dan melestarikan kultur bangsa sekaligus pendidikan karakter (Tilaar, 2012; Tim Peneliti Ekspresi Estetika, 2007). Pendidikan karakter melalui seni tradisi terlihat memungkinkan untuk diterapkan di Indonesia yang memiliki berbagai jenis kesenian daerah. Hal tersebut dapat dimanfaatkan dan dipelajari untuk pendidikan atau dalam istilah yang dipopulerkan oleh Herbert Read adalah pendidikan melalui seni (Read, 1970).

Penelitian terkait pendidikan melalui seni memang sudah banyak dibahas (Brown, 2010; Fachrurrofi, 2019; Romanowski, 2019; Stevens, 2018; Suherman, 2018; Winataputra, 2008; Winton, 2018), namun belum ada penelitian yang membahas tentang pendidikan karakter yang melalui pendidikan seni dari proses penikmatan terhadap seni tradisi di Indonesia. Di dalam pendidikan karakter melalui seni, terdapat istilah penubuhan yang dipopulerkan oleh Merleu-Ponty (Merleau-Ponty, 1992). Penubuhan berarti ketika individu melihat sebuah pertunjukan seni tradisi atau kesenian apapun, maka di dalam dirinya memiliki kekuatan kosmos yang menjadi- kannya menyatu dengan kesenian atau entitas tersebut (Kissell, 2011; MerleauPonty, 1992; Sutton, 2015; Tateo, 2014). Jika dicermati, memang kampanye pendidikan haruslah seperti itu, di mana dalam melakukan kegiatan pendidikan memerlukan penubuhan yang membuat individu menyatu dengan pendidikan tersebut. Penumbuhan tersebut berpotensi membuat peserta didik tidak merasa bahwa dirinya sedang belajar, namun lebih menekankan pada pembelajaran dengan bermain dan pendidikan yang ada dalam permainan, di mana dalam penelitian ini aspek bermain tersebut adalah pertunjukan seni tradisi (Csikszentmihalyi, 2014, 2018; MerleauPonty, 1992).

Berdasarkan jabaran di atas, maka penelitian ini mencoba untuk menjelaskan pendidikan karakter melalui seni tradisi di Indonesia, dalam hal ini adalah Reog di Kabupaten Ponorogo. Reog dipilih, karena Reog sendiri merupakan jenis pertunjukan budaya yang populer di Indonesia, dan Reog dipilih karena jenis pertunjukan kebudayan tersebut dapat dijumpai dalam masyarakat urban, tidak hanya dalam masyarakat pedesaan. Lebih lanjut, penelitian ini turut mengeksplorasi pendidikan karakter melalui fenomenologi penumbuhan yang terjadi ketika individu mengapresiasi pertunjukan seni tradisi di Indonesia khususnya Reog Ponorogo.

\section{METODE}

Metode penelitian ini menggunakan kualitatif naturalistik, dengan pendekatan fenomenologis terhadap fenomena Reog Ponorogo dan keterkaitannya dengan pendidikan karakter. Metode kualitatif naturalistik adalah metode yang menggunakan data yang berupa uraian kalimat tertulis ataupun lisan dari suatu objek yang bertujuan untuk menggunakan hal-hal yang berhubungan dengan keadaan suatu gejala (Denzin \& Lincoln, 2018; Leavy, 2017; Lune \& Berg, 2017). Jenis penelitian tersebut dipilih karena peneliti ingin menjadi instrumen utama dalam mengeksplorasi fenomena pertunjukan Reog Pono- 
rogo. Penelitian dengan pendekatan fenomenologis berfokus pada narasi atas pengamatan peneliti terhadap Reog Ponorogo (Dwyer et al., 2012; Mura \& KhooLattimore, 2018). Selanjutnya, narasi yang dikumpulkan dalam penelitian ini dikembangkan untuk menjadi fitur utama dari penelitian dieksplorasi untuk menjawab permasalahan penelitian. Batasan spasial dalam penelitian ini adalah Kabupaten Ponorogo. Cakupan spasial tersebut dipilih karena mengacu pada tempat asal Reog Ponorogo. Selanjutnya batasan temporal dilakukan dengan batasan bulan JuliDesember 2019. Untuk batasan isi, peneliti membatasi penelitian ini pada aspek pengalaman estetik dan transformasi yang terjadi dalam relevansinya terhadap pendidikan karakter.

Untuk mendapatkan data, penelitian ini menggunakan metode observasi, wawancara, dan studi dokumentasi. Observasi dilakukan terhadap pertunjukan festival Reog Ponorogo selama bulan JuliDesember 2019 di Kabupaten Ponorogo, Jawa Timur. Wawancara dilakukan terhadap penari Reog Ponorogo, warga asli Ponorogo, dan masyarakat umum. Studi dokumentasi dilakukan atas dokumendokumen, foto-foto, serta berita tentang pertunjukan Reog Ponorogo. Data yang dikumpulkan selanjutnya dianalisis secara deskriptif berupa uraian-uraian secara detail tentang kesejarahan Reog Ponorogo, pertunjukannya, pengalaman-pengalaman ketika melihat Reog Ponorogo dan relevansinya terhadap pendidikan karakter. Pendekatan yang digunakan dalam penelitian ini adalah dance studies untuk mengkaji pertunjukan Reog Ponorogo secara lebih spesifik sehingga menunjukkan transformasi yang ada di dalamnya untuk dikaji relevansinya terhadap pendidikan karakter (Mills, 2019; Shkedi, 2019). Dance studies merupakan analisis sebuah pertunjukan yang lebih luas dari sebuah praktik sosial yaitu mengarah para ketubuhan, identitas, transformasi, dan representasi (Foley, 2012; Wilcox, 2016). Reog Ponorogo dalam penelitian ini tidak hanya dipandang sebagai sebuah bentuk namun memiliki unsur lain yang berkenaan dengan sebuah praktik sosial bagi para individu di sekitarnya. Melalui pendekatan ini, penelitian ini mencoba untuk dapat melihat pertunjukan Reog Ponorogo sebagai sebuah seni pertunjukan tradisi budaya Indonesia yang di dalamnya terdapat potensi terkait pendidikan karakter bagi generasi muda.

\section{HASIL DAN PEMBAHASAN}

Budaya dapat didefinisikan sebagai warisan sosial dari komunitas atau masyarakat yang terorganisir yang merupakan pola tanggapan yang telah ditemukan dan ditemukan ketika kelompok telah berinteraksi yang merupakan kombinasi dari kepercayaan, adat, agama, dan seni (Geertz, 1973; Hobsbawm \& Ranger, 2012; Joshi, 2011; Malinowski, 1944). Sementara itu, pendidikan adalah proses dari menanamkan pengetahuan atau memperoleh pengetahuan (Ki Hadjar Dewantara, 2004). Budaya berpotensi berdampak besar pada pendidikan, selain itu pendidikan juga berdampak pada budaya masyarakat.

Pendidikan karakter adalah pendidikan yang memerhatikan, mengembangkan, dan mengutamakan pengembangan etis, intelektual, sosial, dan emosional individu (Rivers, 2016; Shields, 2015). Proses pendidikan karakter merupakan proses pembelajaran berkelanjutan yang memungkinkan individu baik generasi muda maupun dewasa untuk menjadi individu yang bermoral, peduli, kritis, dan bertanggung jawab (Nieven, 1999; Rivers, 2016; Williams, 2017). Pendidikan karakter mewakili hubungan antara pengetahuan, nilai-nilai dan keterampilan yang diperlukan untuk kesuksesan dalam hidup. Pendidikan karakter menjadi penting dan perlu karena masyarakat modern sedang berjuang dengan tren disruptif seperti rasisme, xenophobia, hoax, dan kekerasan. Pendidikan karakter dapat membantu individu membangun karakter yang baik yang pada gilirannya dapat membantu membangun masyarakat yang baik. Pilar nilai- 
nilai pendidikan karakter yang meliputi agama atau relijiusitas, kejujuran, toleransi, kedisiplinan, kerja keras, dan tanggung jawab berkelindan menjadi satu dalam kebudayaan (Stevens, 2018; Timothy J. Bergen, 2014). Indonesia memiliki kearifan lokal yang dimiliki melalui kebudayaan seni tradisinya sehingga memiliki potensi untuk membangun karakter bangsa dan identitas Indonesia yang lebih mumpuni (Gustami, 2007; Soedarsono, 1999). Pendidikan berbasis seni budaya tradisi diharapkan dapat menumbuhkan aspirasi dan semangat generasi muda untuk mengembangkan potensi lokal sehingga kawasan induk budayanya dapat tumbuh pesat sejalan dengan tuntutan globalisasi di era disrupsi. Bentuk seni budaya tradisi di dalamnya terdapat kearifan lokal yang juga berfungsi membentuk manusia untuk menjadi lebih bijaksana dalam menjalani kehidupan.

Pendidikan karakter melalui seni mempertemukan disiplin lain dengan bersama-sama memberikan pengalaman belajar yang memperkaya pengetahuan individu. Seperti contohnya pada anakanak yang tidak nyaman berbicara tentang subjek tertentu yang belum dapat sepenuhnya mengekspresikan diri, mereka belajar bagaimana menggunakan seni untuk mengekspresikan emosi dan kesulitan mereka (Ambarwangi \& Suharto, 2014; Lewis \& Hammer, 2007; Schauert, 2014). Seni membantu mereka mengatasi masalah yang ada dalam hidup mereka dan memberdayakan mereka untuk mencapai potensi maksimal. Hal tersebut didukung oleh argumentasi yang mengatakan bahwa tujuan dari pendidikan adalah untuk menciptakan individu yang efisien dalam berbagai mode ekspresi (Ki Hadjar Dewantara, 2004; Read, 1970; Soemardjo, 2000). Seni yang merupakan kegiatan kreatif harus mengambil fokus inti dari pendidikan dan pada anak-anak kreativitas adalah aspek terpenting dan harus didorong untuk mereka mampu mengekspresikan diri. Pendidikan karakter melalui seni membuka diri melalui kurikulum yang menekankan pada pengembangan kemampuan estetik dan artistik siswa. Mata pelajaran seperti sejarah yang dianggap membosankan oleh siswa dibuat lebih menarik dengan kegiatan bermain peran, maupun pengamatan langsung pertunjukan seni. Reog merupakan salah satu bentuk seni tradisi juga digunakan dalam pendidikan, terutama dalam mengajarkan kedisiplinan, rasa tanggung jawab, cinta tanah air, dan gerak tubuh (Ambarwangi \& Suharto, 2014; Kartomi, 2016). Tarian sangat menarik dan imersif serta merupakan bahasa universal dan melintasi batas dan perbedaan individu untuk menyatukan kesatuan ragam budaya Indonesia dan menyampaikan kesan harmoni (Acolin, 2016; Roberts, 2016; Snoeyenbos \& Knapp, 2018). Ilmu psikoanalisis pendidikan memahami bahwa pengalaman langsung atas fenomena bermanfaat bagi pengetahuan dan pendidikan individu (Csikszentmihalyi, 2014, 2018; Csikszentmihalyi, Latter, \& Duranso, 2017). Hal tersebut didukung dengan kesadaran budaya yang berkembang tentang pentingnya pengalaman kesenian untuk individu. Untuk mendukung hal tersebut, terdapat penekanan pada bentuk-bentuk pendidikan dalam ruangan yang tidak berwujud di ruang kelas yang terlalu fokus pada kognisi abstrak dengan mengorbankan emosi, gerakan, dan proses lain yang berakar pada interaksi tubuh-lingkungan (Pickard, 2018; Tateo, 2014), yaitu melalui apresiasi seni tradisi Reog Ponorogo. Pendeskripsian Reog Ponorogo bagi pendidikan adalah perujudan folklore tentang singa dengan bulu-bulu merak di kepalanya. Saat pertunjukan dihelat, para penonton terpesona dengan pertunjukan yang ditampilkan, walau dalam momen tersebut yang dilihat hanya bentuk visual belum mengarah pada tarian tradisional yang lebih dari sekedar seni pertunjukan. Reog Ponorogo juga memberikan pendidikan relijiusitas dengan melibatkan tampilan supranatural yang menjadi aspek ikonik dari Reog Ponorogo sehingga masyarakat Kabupaten Ponorogo melihatnya sebagai identitas mereka. 
Selain soal relijiusitas, pendidikan tentang identitas nasional melalui folklore kesejarahan juga tersampaikan melalui Reog Ponorogo. Folklore yang paling populer tentang Reog Ponorogo adalah tentang Ki Ageng Kutu, seorang punggawa Majapahit yang hidup pada abad ke-15 yang bertugas pada periode raja terakhir Kerajaan Majapahit (Ambarwangi \& Suharto, 2014; Kartomi, 2016). Selama periode ini, kerajaan Majapahit mulai dalam masa kemunduran. Ki Ageng Kutu meramalkan bahwa kedigdayaan kerajaan akan berakhir dan memutuskan untuk meninggalkan istana. Sampai akhirnya tiba di Ponorogo dan mendirikan sebuah lembaga untuk mengajar seni bela diri anak muda dan ilmu kejawen dengan harapan bahwa murid-muridnya akan membawa kembali masa kejayaan Kerajaan Majapahit. Namun demikian, jumlah pengikutnya kecil dan tidak akan mampu mengambil kekuatan tentara Majapahit. Oleh karena itu, untuk menyampaikan pesannya kepada khalayak yang lebih luas, dan untuk mendapatkan dukungan mereka, Ki Ageng Kutu merancang Reog Ponorogo. Strategi ini berhasil, dan tariannya menjadi sangat populer di kalangan masyarakat Ponorogo. Raja Majapahit sadar akan situasi ini dan sebuah pasukan dikirim untuk melawan Ki Ageng Kutu dan para pengikutnya. Meskipun sekolah hancur, para kolega dan budayawan terus mempraktikkan Reog Ponorogo secara rahasia. Seiring berkembangnya zaman, alur cerita dalam Reog Ponorogo ditambahkan bersama dengan karakter baru dari cerita rakyat Ponorogo. Reog Ponorogo akhirnya menjadi tarian tradisional penduduk Ponorogo dan menjadi identitas budaya Kabupaten Ponorogo. Dari penjabaran tersebut, tentunya semakin menunjukkan bahwa pendidikan nasionalisme kearifan lokal dapat dijelaskan dengan baik oleh pertunjukan Reog Ponorogo.

Metafor-metafor sebagai simbol aspek yang akan dijelaskan kepada masyarakat disimbolisasikan dengan baik.
Misalnya, dalam pertunjukan Reog Ponorogo terdapat sejumlah karakter dalam bentuk tarian tradisional yang salah satunya adalah jathil, yang mewakili pasukan Kerajaan Majapahit. Secara tradisional, penari pria dengan penampilan feminimlah yang memainkan peran ini walaupun saat ini perempuan memilik andil dalam memainkan peran ini. Simbolisme lain dari Reog Ponorogo juga dapat dilihat dalam karakter Singa Barong, sosok singa yang menakutkan dengan bulu-bulu merak di kepalanya. Singa mewakili raja Majapahit, sementara bulu mewakili ratu atau selirselirnya (Daddesio, 2013; Hanna, 2010). Hal ini dimaksudkan sebagai kritik terhadap raja, yang meskipun terlihat garang namun dikendalikan oleh ratu. Oleh karenanya, pendidikan gender turut masuk dalam simbolisasi yang ada dalam Reog Ponorogo. Terdapat pula dhadak merak yang merupakan kombinasi dari tiga jiwa yaitu manusia, harimau, dan merak yang melambangkan kemewahan dan kemuliaan dengan pesan bahwa kekuatan manusia tertinggi ada pada raja yang dilambangkan oleh harimau, sedangkan untuk burung merak dibenarkan sebagai hewan peliharaan Tuhan yang begitu agung untuk kegiatan keagamaan (al Faruqi, 2015; Arifani, 2010; Krismawati, Warto, \& Suryani, 2018). Lebih lanjut, nilai-nilai agama dalam Reog Ponorogo disampaikan melalui seperangkat gamelan yang digunakan dalam pertunjukannya yang berisi pesan atau nilai untuk mengajak seseorang agar selalu mempercayai kekuatan Tuhan Yang Maha Kuasa.

Setelah menjelaskan pengantar pendidikan melalui Reog Ponorogo, maka berlanjut pada transformasi dan pengalamanpengalaman yang ada di dalam pertunjukannya. Di dalam pertunjukan Reog Ponorogo, narasi identitas para penarinya menyiratkan bahwasanya mereka mendalami perasaan memiliki Reog Ponorogo. Di dalam beberapa kasus mereka mengalami trans yang justru memaksimalkan praktik koreografi yang mereka alami (Ivey, 2011). Tubuh dapat ditulis melalui pengalaman 
menari dalam konteks budaya yang sudah melekat lama dan melegenda (Sansom, 2018; Weintraub, 2018). Bagi beberapa penari, pengalaman belajar menari Reog Ponorogo menjadikan dirinya transformatif menjadi benar-benar menubuh dengan Reog Ponorogo (Shukla, 2014; Sutton, 2015; Tateo, 2014). Ketika menari, asumsi restrukturisasi untuk berpikir secara berbeda tentang subjek atau masalah tertentu terdefinisikan sebagai pembelajaran untuk membuatnya lebih inklusif, reflektif, dan secara emosional mampu mengubah karakter seseorang. Transformasi turut memasuki area pendidikan karakter yang dialami oleh para penari Reog Ponorogo ketika mereka benar-benar memahami Reog Ponorogo, maka dengan kesukarelaannya menjadi agen budaya tradisi untuk dunia global (Foley, 2016; Iacono \& Brown, 2016). Selain itu, unsur transformatif muncul melalui berbagai pengalaman seni dalam hal ini adalah pengalaman tari seperti pengalaman penubuhan, pengalaman kreatif, dan pengalaman pedagogis (Sansom, 2011, 2017; Sheets-Johnstone, 2012). Pengalaman seperti itu tidak selalu dinyatakan secara eksplisit, tetapi lebih tepatnya dapat dideteksi ketika mereka menggambarkan perasaan mental dan fisik yang mereka alami ketika menari. Refleksi proses kreatif ini mendorong individu untuk mengamati, menulis, merefleksikan, mendiskusikan, mengevaluasi, dan memberikan rekomendasi untuk fitur-fitur karya Reog Ponorogo dalam rangka mengembangkan cita-cita estetika individu untuk melihat, membuat dan melakukan gerakan seni tradisi Indonesia. Lebih lanjut, berpijak pada pernyataan tentang bagaimana seseorang menyebarkan pengetahuan tidak dapat dipisahkan dari bagaimana cara belajar, maka pelaku Reog Ponorogo mengungkapkan bahwa mereka mengalami momen-momen pedagogis transformatif dan pergeseran pengetahuan pedagogis ketika mempelajari Reog Ponorogo (Carr, 2014; Kurath et al., 2017; Risner, 2012). Pergeseran dalam pengetahuan pedagogis sering melalui mengalami momen pembe- lajaran transformatif yang berkaitan dengan pengalaman estetis individu.

\section{SIMPULAN}

Indonesia yang memiliki berbagai macam budaya salah satunya melalui Reog Ponorogo mampu memunculkan transformasi pengalaman fenomenologis ke dalam pendidikan karakter yang terjalin secara halus dan interdisiplin. Konsep-konsep yang ada di dalam Reog Ponorogo tidak bersifat eksklusif, namun berkelindan untuk mendukung adanya pengalaman estetis yang berdampak pada pendidikan karakter dan berkontribusi pada bidang lainnya dalam semangat interdisiplin. Pengalaman estetis atas Reog Ponorogo yang terjadi dalam praktik kebudayaan yang mampu memaparkan pendidikan karakter secara metafor dalam simbolisasinya. Masa depan pendidikan karakter melalui pertunjukan seni budaya tradisi perlu ditegaskan kembali, di mana pendidikan melalui seni harus ditandai dengan keterbukaan, eksplorasi, penemuan, integrasi, atau sebagai alternatif. Perlu adanya jaringan dialog pendidikan berbasis kebudayaan antara dan di antara komponen transaksi praktik budaya tradisi. Melalui pemikiran ini para pendidik, pemerhati budaya, dan masyarakat mampu menciptakan suasana di mana transformasi seni budaya menuju pendidikan karakter terjadi; mengembangkan lingkungan di mana pendekatan budaya sangat dipertimbangkan dan siswa dipersiapkan dengan keterampilan budaya dan praktik refleksif yang dapat dilakukan sebagai pendukung serta media belajar setiap generasi muda.

Pendidikan karakter dan budaya saling mempengaruhi dengan cara pendidikan memainkan peran utama dalam transmisi budaya, hal ini dicapai ketika pelestarian melalui pertunjukan budaya tradisi dilakukan dari satu generasi ke generasi lainnya. Pendidikan dalam posisi ini adalah alat yang digunakan untuk mengirimkan nilai-nilai sosial dan ide-ide kepada generasi muda dan yang akan datang, di mana hal tersebut masuk dalam pendidikan 
karakter. Hal tersebut juga didukung dengan budaya yang dapat dikembangkan melalui pendidikan untuk membawa perubahan yang diinginkan baik dalam budaya maupun nilai-nilai untuk kemajuan dan perkembangan masyarakat. Pertunjukan Reog Ponorogo memberikan nilai sosiologis dalam proses kesenjangan sosial ketika menikmati pertunjukan. Dari seluruh kalangan masyarakat berkumpul dalam ruang publik yang menjadi panggung pertunjukan Reog Ponorogo. Hal tersebut turut menjadi bukti bahwasanya Reog Ponorogo sebagai kesenian tradisi budaya Indonesia mampu menjembatani kesenjangan antara status sosial masyarakat, mempertimbangkan norma-norma budaya dengan teknologi yang sedang berkembang sebagai ujud pendidikan karakter.

\section{UCAPAN TERIMA KASIH}

Penulis mengucapkan terima kasih kepada semua pihak yang telah membantu dalam pembuatan tulisan ini. Semoga dapat bermanfaat, khususnya bagi penulis, umumnya bagi semua pembaca.

\section{CATATAN PENULIS}

Penulis menyatakan bahwa tidak ada konflik kepentingan terkait publikasi artikel ini. Penulis mengkonfirmasi bahwa data dan artikel ini bebas plagiarisme.

\section{PUSTAKA RUJUKAN}

Acolin, J. (2016). The Mind-Body Connection in Dance/Movement Therapy: Theory and Empirical Support. American Journal of Dance Therapy, 38(2), 311-333. https://doi.org/10.1007/s10465-0169222-4

al Faruqi, L. I. (2015). Dance as an Expression of Islamic Culture. Dance Research Journal, 10(2), 6. https://doi.org/10.2307/1477998

Ambarwangi, S., \& Suharto, S. (2014). Reog As Means of Students' Appreciation and Creation in Arts and Culture Based on the Local Wisdom.
Harmonia: Journal of Arts Research and Education, 14(1), 37-45. https://doi.org/10.15294/harmonia.v1 $4 \mathrm{i} 1.2789$

Arifani, M. A. (2010). Model Pengembangan Dakwah Berbasis Budaya Lokal. Jurnal Ilmu Dakwah: Academic Journal for Homiletic Studies, 5(15), 849-878. https://doi.org/10.15575/IDAJHS.V5I 15.425

Bastos, F. (2010). New Media Art Education. Art Education, 63(1), 7-9.

Berkowitz, M. W., \& Bier, M. C. (2014). Research Based Character Education. Annals of the American Academy of Political and Social Science, 591, 7285. https://doi.org/10.1177/00027162032 60082

Bowen, D. H., \& Kisida, B. (2017). The Art of Partnerships: Community Resources for Arts Education. The Phi Delta Kappan, 98(7), 8-14.

Brown, S. (2010). Building Character through Shadow Puppetry. Art Education, 57(1), 8-25.

Carr, C. (2014). Dance Education, Skill, and Behavioral Objectives. The Journal of Aesthetic Education, 18(4), 67-76.

Csikszentmihalyi, M. (2014). Applications of Flow in Human Development and Education.

https://doi.org/10.1007/978-94-0179094-9_2

Csikszentmihalyi, M. (2018). Flow: The Psychology of Optimal Experience. https://doi.org/wiretap

Csikszentmihalyi, M., Latter, P., \& Duranso, C. W. (2017). Running Flow. London: Human Kinetics.

Daddesio, T. C. (2013). On Minds and Symbols: The Relevance of Cognitive Science for Semiotics. https://doi.org/10.1515/97831109030 
03

Davies, I., Gorard, S., \& McGuinn, N. (2015). Citizenship Education and Character Education : Similarities and Contrasts. British Journal of Educational Studies, 53(3), 341-358. Retrieved from http://www.jstor.org/stable/3699247

Denzin, N. K., \& Lincoln, Y. S. (Eds.). (2018). The SAGE Handbook of Qualitative Research (Fifth Edit). https://doi.org/10.1007/s11229-0171319-x

Dewey, J. (1980). Art as Experience. New York: Perigee Books.

Dwyer, L., Gill, A., Seetaram, N., Dwyer, L., Gill, A., \& Seetaram, N. (Eds.). (2012). Handbook of Research Methods in Tourism: Quantitative and Qualitative Approaches. London: Edward Elgar.

Eisenhauer, J. F. (2006). Beyond Bombardment: Subjectivity, Visual Culture, and Art Education. Studies in Art Education, 47(2), 155-169.

Fachrurrofi, F. (2019). Tradisi Babanyo di Kabupaten Bandung Barat untuk Bahan Pembelajaran di SMA. Lokabasa-Journal of Language Studies, Literature, and Culture Regions and His Teachings, 10(1), 108-116.

https://doi.org/10.17509/jlb.v10i1

Foley, C. E. (2012). Ethnochoreology as a Mediating Perspective in Irish Dance Studies. New Hibernia Review, 16(2), 143-154.

https://doi.org/10.1353/nhr.2012.0024

Foley, C. E. (2016). Postcolonial Agency, Proactive Archiving, and Applied Ethnochoreology: The National Dance Archive of Ireland. Cesky Lid, 104(4), 495-511.

https://doi.org/10.21104/CL.2017.4.0 5

Geertz, C. (1973). The Interpretation of
Cultures. New York: Basic Book.

Graham, G. (1997). Philosophy of the Art. London: Routledge.

Gustami, S. (2007). Butir Butir Mutiara Estetika Timur: Ide Dasar Penciptaan Seni Kriya Indonesia. Yogyakarta: Prasista.

Hanna, J. L. (2010). Dance and Sexuality: Many Moves. Journal of Sex Research, 47(2-3), 212-241. https://doi.org/10.1080/00224491003 599744

Hetrick, L. J. (2019). My Desire for Art Education. Studies in Art Education, 54(3), 273-276.

Hobsbawm, E., \& Ranger, T. (2012). The Invention of Tradition. https://doi.org/10.1017/CBO9781107 295636

Iacono, V. Lo, \& Brown, D. H. K. (2016). Beyond Binarism: Exploring a Model of Living Cultural Heritage for Dance. Dance Research: The Journal of the Society for Dance Research, 34(1), 84-105.

https://doi.org/10.3366/drs.2016.0147

Ivey, B. (2011). Values and Value in Folklore. Journal of American Folklore, 124(491), 6-18. https://doi.org/10.5406/jamerfolk.124 .491 .0006

Joshi, R. J. (2011). High Performance Culture. Indian Journal of Industrial Relations, 37(Developing a Culture of High Performance), 18-30.

Kartomi, M. J. (2016). Performance, Music and Meaning of Réyog Ponorogo. Indonesia, 22(22), 84-130.

Ki Hadjar Dewantara. (2004). Karya Ki Hadjar Dewantara Bagian I: Pendidikan. Yogyakarta: Majelis Luhur Persatuan Taman Siswa.

Kissell, J. L. E. E. (2011). Embodiment. Theoretical Medicine, 1(1), 1-4. 
Kraus, R. (2014). Transforming Spirituality in Artistic Leisure: How the Spiritual Meaning of Belly Dance Changes Over Time. Journal for the Scientific Study of Religion, 53(3), 459-478. https://doi.org/10.1111/jssr.12136

Krismawati, N. U., Warto, \& Suryani, N. (2018). Eksistensi Warok Dan Gemblak di tengah Masyarakat Muslim Ponorogo Tahun 1960-1980. Religió: Jurnal Studi Agama-Agama, $8(1), 116-138$.

Kuntz, L. F. (2014). Religion and Character Education. Religious Education, 49(4), 255-263. https://doi.org/10.1080/00344085404 90403

Kurath, G. P., Brandel, R., Chilkovsky, N., List, G., Laubin, R., Laubin, G., ... Wright, F. B. (2017). Dance Ethnology, Dance Education, and the Public. Ethnomusicology, 7(3), 234247.

Leavy, P. (2017). Research Design: Quantitative, Qualitative, Mixed Methods, Arts-Based, and Community-Based Participatory Research Approaches. Retrieved from http://www.ghbook.ir/index.php?nam فرهن \& نوين nline\&book_id $=13650 \&$ page $=73 \& \mathrm{ch}$ khashk $=$ ED9C9491B4\&Itemid $=218 \&$ lang $=$ fa\&tmpl=component

Lewis, J. R., \& Hammer, O. (Eds.). (2007). The Invention of Sacred Tradition. https://doi.org/10.1017/CBO9780511 488450.004

Lune, H., \& Berg, B. L. (2017). Qualitative Research Methods for the Social Sciences (Ninth edit). Essex: Pearson.

Madeja, S. S. (2009). The Art Curriculum: Sins of Omission. Art Education, 33(6), https://doi.org/10.2307/3192454

24.

Malinowski. (1944). A Scientific Theory of
Culture and Other Essays. New York: Oxford University Press.

$\begin{array}{ccr}\text { Merleau-Ponty, } & \text { M. } & \text { (1992). } \\ \text { Phenomenology } & \text { Of } & \text { Perception. } \\ \text { London: Routledge. } & & \end{array}$

Mills, K. A. (2019). Big Data for Qualitative Research. In Routledge Focus.

https://doi.org/10.4324/97804290564 13

Moran, J. (2002). Interdisciplinarity. New York: Routledge.

Mura, P., \& Khoo-Lattimore, C. (Eds.). (2018). Asian Qualitative Research in Tourism: Ontologies, Epistemologies, Methodologies, and Methods. Singapore: Springer Singapore.

Nieven, N. (1999). Design Approaches and Tools in Education and Training. London: Kluwer Academic Publisher.

Pickard, A. (2018). Exploring Embodiment through Choreographic Practice. Frontiers in Psychology, 9(OCT), 14.

https://doi.org/10.3389/fpsyg.2018.01 920

Read, H. (1970). Education Through Art. London: Faber and Faber.

Risner, D. (2012). Rehearsing Heterosexuality: "Unspoken" Truths in Dance Education. Dance Research Journal, 34(2), 63-78.

Rivers, T. M. (2016). Ten Essentials for Character Education. The Journal of General Education, 53(3), 247-260.

Roberts, N. G. (2016). Embodying Self: A Dance/Movement Therapy Approach to Working with Concealable Stigmas. American Journal of Dance Therapy, $38(1)$, 63-80. https://doi.org/10.1007/s10465-0169212-6

Romanowski, M. H. (2019). Through the Eyes of Teachers: High School Teachers' Experiences with Character 
Education. American Secondary Education, 34(1), 6-23.

Sampurno, M. B. T. (2017). Learning through children's paintings. Proceeding of 2nd International Conference of Arts Language And Culture, 405-413.

Sampurno, T. (2015). Seni, Melukis, dan Anak Autis: Penanganan dan Pengembangan melalui Seni dan Cara Mengevaluasi Karya Anak Autis. Yogyakarta: Psikosain.

Sansom, A. N. (2011). A Vision for Dance. Counterpoints, 98(2), 2-2. https://doi.org/10.1021/cen-09802editorial

Sansom, A. N. (2017). What Is Dance and Why Dance? Movement in the Early Years. Counterpoints, 407(156), 2538.

Sansom, A. N. (2018). The Body in Education. Counterpoints, 407(201), 1013-1026.

https://doi.org/10.1007/978-3-31972761-5_71

Schauert, P. (2014). Managing Culture: Discipline, Artistry, and Alternative Education in Ghana's State Dance Ensembles. Africa Today, 60(3), 3-33.

Sheets-Johnstone, M. (2012). From Movement to Dance. Phenomenology and the Cognitive Sciences, 11(1), 3957. https://doi.org/10.1007/s11097011-9200-8

Shields, D. L. (2015). Character as the Aim of Education. The Phi Delta Kappan, 78(6), 428-439.

Shkedi, A. (2019). Introduction to Data Analysis in Qualitative Research. Singapore: Springer International Publishing.

Shukla, P. (2014). Northern European Folklore: Fieldwork , Heritage, and Embodiment. Journal of Folklore Research, 51(3), 249-252.
Snoeyenbos, M. H., \& Knapp, C. A. (2018). Dance Theory and Dance Education. The Journal of Aesthetic Education, 13(3), 17-30.

Soedarsono, R. M. (1999). Seni Pertunjukan Indonesia dan Pariwisata. Bandung: Masyarakat Seni Pertunjukan Indonesia.

Soemardjo, J. (2000). Filsafat Seni. Bandung: Penerbit ITB.

Stevens, M. L. (2018). Culture and Education. Annals of the American Academy of Political and Social Science, 619(1), 97-113. https://doi.org/10.1177/00027162083 20043

Suherman, A. (2018). Jabar Masagi: Penguatan Karakter Bagi Generasi Milenial Berbasis Kearifan Lokal. Lokabasa-Journal of Language Studies, Literature, and Culture Regions and His Teachings, 9(2), 107. https://doi.org/10.17509/jlb.v9i2.1567 8

Sutton, J. (2015). Memory and the Extended Mind: Embodiment, Cognition, and Culture. Cognitive Processing, 6(4), 223-226. https://doi.org/10.1007/s10339-0050022-x

Tateo, L. (2014). The Dialogical Dance: Self, Identity Construction, Positioning and Embodiment in Tango Dancers. Integrative Psychological and Behavioral Science, 48(3), 299321. https://doi.org/10.1007/s12124014-9258-2

Tilaar, H. A. R. (2012). Perubahan Sosial dan Pendidikan. Jakarta: Rineka Cipta.

Tim Peneliti Ekspresi Estetika. (2007). Pengembangan Model Pembelajaran Ekspresi Estetika Inovatif Untuk Pendidikan Dasar. Jakarta: Departemen Pendidikan Nasional: Badan Penelitian dan Pengembangan 
Pendidikan.

Timothy J. Bergen, J. (2014). Culture, Character, and Citizenship. Journal of Thought, 29(3), 7-16.

Weintraub, A. N. (2018). "Dance Drills, Faith Spills": Islam, Body Politics, and Popular Music in Post-Suharto Indonesia. Popular Music, 27(3), 367392.

https://doi.org/10.1017/S0261143008 102185

Wilcox, E. E. (2016). Beyond Internal Orientalism: Dance and Nationality Discourse in the Early People's Republic of China, 1949-1954. Journal of Asian Studies, 75(2), 363386.

https://doi.org/10.1017/S0021911815 002090
Williams, M. K. (2017). John Dewey in the 21 st Century. Journal of Inquiry \& Action in Education, 9(1), 91-102.

Winataputra, U. S. (2008). Multikulturalisme-Bhinneka Tunggal lka Dalam Perspektif Pendidikan Kewarganegaraan Sebagai Wahana Pembangunan Karakter Bangsa Indonesia. Jurnal Pendidikan Dan Kebudayaan, Vol. 14, pp. 1009-1027. https://doi.org/10.24832/jpnk.v14i75. 364

Winton, S. (2018). The Appeal(s) of Character Education in Threatening Times: Caring and Critical Democratic Responses. Comparative Education, 44(3), 305-316. https://doi.org/10.1080/03050060802 264843 